\title{
Increased expression of CD40 ligand (CD154) on CD4+ T cells as a marker of disease activity in rheumatoid arthritis
}

Beate Berner, Gabriele Wolf, Klaus M Hummel, Gerhard A Müller, Monika A Reuss-Borst

\begin{abstract}
Objectives-The interaction between the activation induced surface glycoprotein CD40L (ligand) (CD154) on CD4+ T cells and its receptor CD40, which is expressed on various cell types, plays a crucial part in numerous cell mediated and humoral immune reactions that may be of pathogenetic importance in rheumatoid arthritis (RA). To further evaluate the pathogenetic role of CD40L in RA, expression of CD40L and various other $T$ cell activation antigens as well as costimulatory molecules was investigated on CD4+ T cells in RA by flow cytometry.
\end{abstract}

Methods-Two colour flow cytometry was used to determine the percentage of CD4+ T cells expressing CD40L, CD69, CD25, HLA-DR, CD39, CD27 and CD28 in peripheral blood (PB) of $62 \mathrm{RA}$ patients in comparison to 20 healthy controls (HC). Disease activity was assessed by clinical, laboratory and radiological examination. Status of clinical remission of $R A$ was evaluated according to the ACR preliminary criteria for complete clinical remission of RA.

Results-CD40L was expressed on $>10 \%$ of CD4+ T cells in $29 \%$ of RA patients thus defining a CD40L ${ }^{\text {hight }}$ patient group. Disease activity as estimated by $\mathrm{C}$ reactive protein, rheumatoid factor and status of clinical remission of disease $(p=0.049)$ was higher in this subgroup than in the RA CD40L ${ }^{\text {low }+}$ group. Expression of CD69, CD25, and HLA-DR was significantly increased in both RA patient groups in comparison with HC. However, the percentage of CD39+ $\mathrm{CD} 4+\mathrm{T}$ cells was increased only in the RA CD40L $\mathrm{L}^{\text {high+ }}$ subgroup (versus HC $p=0.019$, versus $R A$ CD40L $\left.{ }^{\text {low }+} p=0.044\right)$. Furthermore, expression of CD40L and CD39 on CD4+ T cells correlated positively as estimated by Spearman rank correlation $(p<0.001)$. The percentage of CD4+ $T$ cells lacking the costimulatory molecules $\operatorname{CD27}$ ( $p=$ $0.002)$ and CD28 $(p=0.026)$ was increased in RA CD40L ${ }^{\text {low+ }}$ patients in comparison with HC.

Conclusions-These data suggest that increased expression of CD40L on CD4+ $T$ cells in RA indicates prolonged and increased activation of CD4+ T lymphocytes and is associated with active disease and possibly an unfavourable prognosis.
Whether this phenotypically defined RA CD40L ${ }^{\text {hight }}$ subgroup will preferentially respond to an anti-CD40L antibody treatment remains to be elucidated.

(Ann Rheum Dis 2000;59:190-195)

The ability of $\mathrm{T}$ lymphocytes to transmit signals to various other cell types via distinct cell contact dependent mechanisms has been known for over a decade. CD40L (ligand) (CD154), a $33 \mathrm{kDa}$ activation induced $\mathrm{T}$ cell surface glycoprotein, which is transiently expressed on activated, but not resting CD4+ T cells $^{1}$ is crucially involved in this cell-cell signalling process by binding to CD40. This phosphorylated glycoprotein belonging to the tumour necrosis factor receptor (TNFR) family ${ }^{23}$ is expressed on various cell types such as B cells, vascular endothelial cells, monocytes/macrophages, dendritic cells and fibroblasts. Thus, CD40L-CD40 interactions are involved in humoral and numerous cell mediated immune responses. ${ }^{3-5}$

Ligation of activated CD40L + CD4+ T cells to CD40 expressed on endothelial cells, for example, results in upregulation of certain adhesion molecules such as E-selectin (CD62E), VCAM-1 (CD106) or ICAM-1 (CD54) thus increasing leucocyte margination and diapedesis. ${ }^{4}$ Activation of histiocytes, dendritic cells and/or monocytes/macrophages by CD40L-CD40 signalling induces the production of chemokines and inflammatory cytokines as well as the synthesis of nitric oxide (NO) and metalloproteinases. ${ }^{4}$ Interaction of CD40L+ CD4+ T cells (that is, T helper cells) with CD40 on B cells causes B cell proliferation and differentiation, isotype switching and formation of B memory cells. ${ }^{5}$

The clinical importance of CD40L expression in vivo is further highlighted by studies of the hyper-IgM-syndrome. This human $\mathrm{X}$-linked immunodeficiency characterised by absent or low levels of IgG, IgA and IgE in serum, but normal or increased levels of $\operatorname{IgM}$ and defects in $\mathrm{T}$ cell mediated immunity is caused by mutations in the CD40L gene that result in a lack of functional expression of CD40L on activated T cells. ${ }^{6}$

In patients with systemic lupus erythematosus (SLE) baseline expression of CD40L and CD40L regulation was recently shown to be changed. ${ }^{78}$ Furthermore, anti-CD40L antibody treatment in mice produced longlasting disease remissions stressing the pathogenetic
Accepted for publication 2 November 1999 
importance of CD40L-CD40 interactions in murine SLE. ${ }^{9-11}$

With regard to rheumatoid arthritis (RA), the most frequent autoimmune rheumatic disease characterised by chronic inflammation and proliferation of the synovium and consecutive cartilage and bone destruction, the pathogenetic importance of CD40L-CD40 interactions remains to be elucidated, in particular as the contribution of $\mathrm{T}$ cells to RA has been a matter of debate for years. Several lines of evidence, however, support the hypothesis of a $\mathrm{T}$ cell driven disease such as the observation that $\mathrm{T}$ cells are the dominant cell population in the synovial infiltrate, the association with certain MHC class II molecules and at least the partial therapeutic effect of $\mathrm{T}$ cell depletion. ${ }^{12}$ In this study, we provide evidence that the activation induced $\mathrm{T}$ cell antigen CD40L may finally prove to be such an important marker of disease activity and possibly unfavourable prognosis. Therefore, the expression of CD40L by $\mathrm{CD} 4+\mathrm{T}$ cells was investigated in 62 peripheral blood (PB) and 10 synovial fluid (SF) samples of patients with RA in comparison with 20 healthy controls (HC) and results were correlated with clinical and laboratory disease status.

\section{Methods}

Heparinised PB samples of 62 patients with $\mathrm{RA}$ and $20 \mathrm{HC}$ were investigated. All patients fulfilled the ARA revised criteria $1987 .{ }^{13}$ Patients (51 women and 11 men) ranged in age from 25 to 77 years (mean age 58.4). By clinical and radiological evaluation patients were categorised as having early disease (that is, no radiological evidence of bone erosions, no extra-articular features) (10 patients), progressive disease (that is, continous disease activity, radiological evidence of bone erosions, possibly extraarticular features) (51 patients) and late disease (that is, disease duration of many years, residual joint damage) (one patient). Extraarticular features were present in nine patients (four with rheumatoid nodules, four with a sicca syndrome and one with a vasculitis). Disease activity of RA was assessed by level of $C$ reactive protein $(\mathrm{CRP})$. Sixty six per cent of $R A$

Table 1 Patient characteristics

\begin{tabular}{|c|c|c|}
\hline & $\begin{array}{l}R A C D 40 L^{\text {high }} \\
(n=18)\end{array}$ & $\begin{array}{l}R A C D 40 L^{\text {low }+} \\
(n=44)\end{array}$ \\
\hline Mean disease duration (range) in years & $7(0.5-25)$ & $7(0.5-40)$ \\
\hline Mean age (range) in years & $54.6(29-75)$ & $61.5(25-77)$ \\
\hline Male/female & $4 / 14$ & $7 / 37$ \\
\hline \multicolumn{3}{|l|}{ State of disease } \\
\hline \multicolumn{3}{|l|}{ Extraarticular features } \\
\hline nodules / sicca syndrome / vasculitis & $1 / 2 / 0$ & $3 / 2 / 1$ \\
\hline Increased CRP level & $15(83 \%)$ & $28(64 \%)$ \\
\hline Mean (SD) CRP (mg/l) & $30.2(24.1)$ & $36.5(34.7)$ \\
\hline Positive RF & $16(89 \%)$ & $32(73 \%)$ \\
\hline Mean (SD) RF (IU/ml) & $292.8(306.3)$ & $240.5(453.1)$ \\
\hline Complete Remission & $0(0 \%)$ & $9(21 \%)$ \\
\hline \multicolumn{3}{|l|}{ DMARD medication } \\
\hline methotrexate & 10 & 20 \\
\hline sulfasalazine & 2 & 8 \\
\hline hydroxychloroquine & 0 & 2 \\
\hline cyclosporin A & 3 & 0 \\
\hline no DMARD & $6(33 \%)$ & $15(34 \%)$ \\
\hline
\end{tabular}

Characteristics of RA CD40L hight $(n=18)$ and RA CD40L lowt $(n=44)$ patients. SD: standard deviation, CRP: $\mathrm{C}$ reactive protein, RF: rheumatoid factor, DMARD: disease modifying antirheumatic drug. patients received disease modifying antirheumatic drugs (DMARD). Status of clinical remission of disease was determined according to the ACR preliminary criteria for complete clinical remission of RA. ${ }^{14}$ Table 1 gives the patient characteristics. Additionally, SF was obtained from 10 patients with RA by arthrocentesis.

\section{DIRECT IMMUNOFLUORESCENCE AND FACS} ANALYSIS

Immunophenotypical analysis was performed using a large panel of directly labelled monoclonal antibodies against various lymphoid differentiation and activation antigens. Antibodies against CD27 (clone M-T271), CD28 (clone CD28.2), CD39 (clone Tü 66) and CD40L (clone TRAP 1) were purchased from Pharmingen (San Diego, CA, USA), antibodies against CD25 (clone B1.49.9) were obtained from Coulter-Immunotech Diagnostics (Hamburg, Germany). Antibodies against CD3 (Leu 4), CD4 (Leu 3a), CD69 (Leu 23) as well as $\gamma 1 / \gamma 2$-controls were purchased from Becton Dickinson (San José, CA, USA). Results of CD40L expression were reproduced by using another two monoclonal antibodies against CD40L, clone 89-76 (Becton Dickinson, San José, CA, USA) and clone 24-31 (Ancell Corporation, Bayport, MN, USA).

Briefly, $20 \mu \mathrm{l}$ fluorescein isothiocyanate (FITC) or phycoerythrin (PE) conjugated monoclonal antibody was given to $200 \mu \mathrm{l}$ heparinised PB and incubated for 15 minutes. Two ml FACS-Lysing-Solution (Becton Dickinson, San José, CA, USA) was added and incubated for 15 minutes. Cells were then washed twice and resuspended in phosphate buffered saline (PBS) (Biochrom KG, Berlin, Germany) for flow cytometry. SF was drawn aseptically into heparinised tubes. SF mononuclear cells were isolated by Ficoll (Biochrom, Berlin, Germany) gradient centrifugation. Then $2 \times 10^{5}-1 \times 10^{6}$ cells in $200 \mu \mathrm{l}$ PBS were incubated with $20 \mu \mathrm{l}$ FITC or PE labelled monoclonal antibody for 15 minutes. Cells were washed twice and resuspended in PBS for analysis.

For two colour analysis PB and SF cells were analysed on a FACS-Calibur (Becton Dickinson, San José, CA, USA) using cellquest software (Becton Dickinson, San José, CA, USA). Data of 10000 cells/sample were collected for forward light scatter (FSC) and sideward light scatter (SSC) in linear scale, for fluorescein (530 nm band pass (bp)) and phycoerythrin (580 nm bp) fluorescence in log scale. Analysis was done by gating on mononuclear cells in FSC/SSC dot plots. Non-specific immunofluorescence was determined by using negative control antibodies and subtracted from specific immunofluorescence. The percentage of FITC and PE positive cells and the mean fluorescence levels were calculated.

IMMUNOHISTOCHEMISTRY

Six $\mu \mathrm{m}$ frozen cryostat sections of synovial tissue (ST) of a RA patient were analysed for CD40L expression by direct immunofluorescence. Sections were air dried and fixed in 


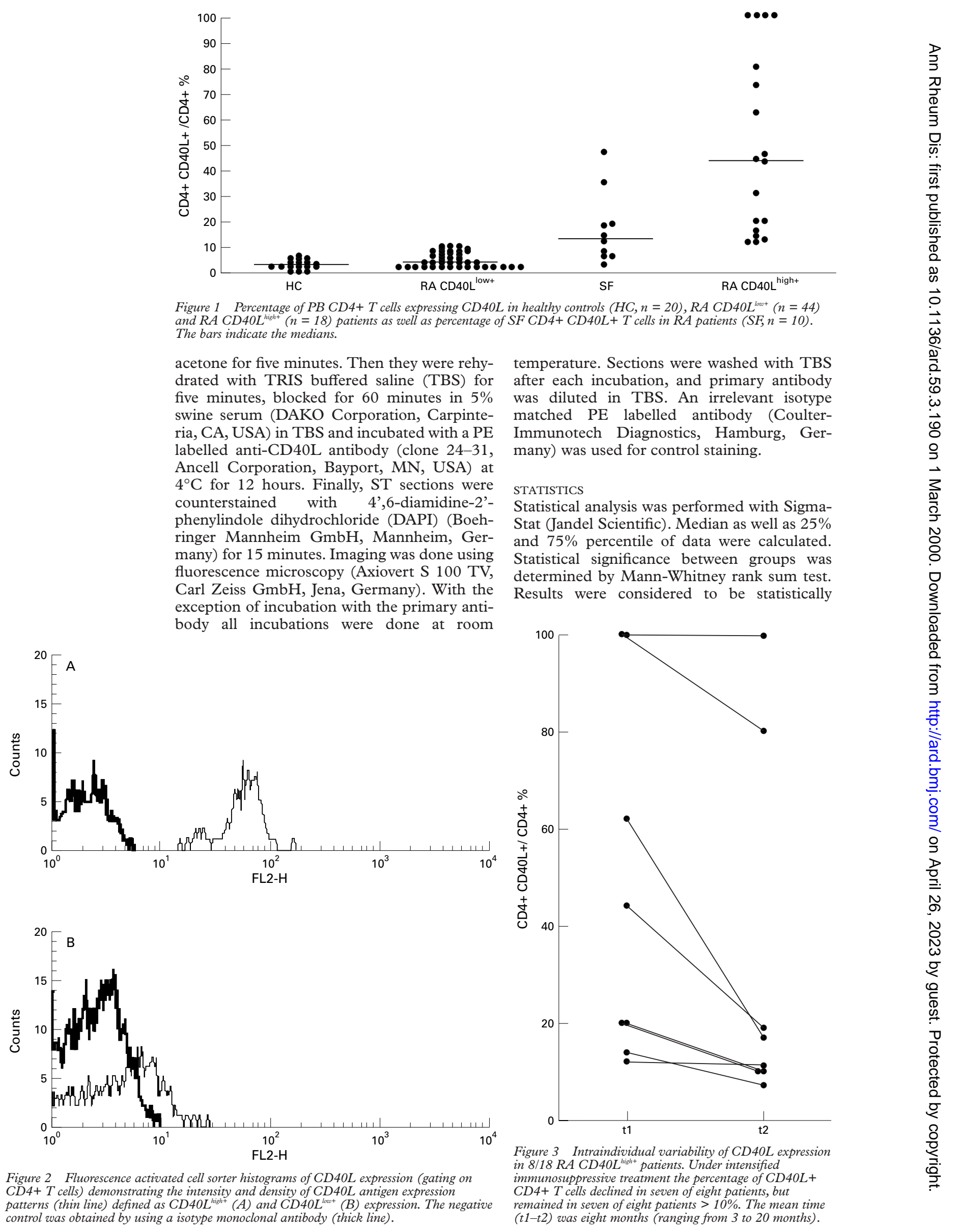


Table 2 Expression of activation and costimulatory molecules on PB CD4OL hight and CD4OL ${ }^{\text {low }} \mathrm{CD}^{\text {he }} \mathrm{T}$ cells in RA

\begin{tabular}{|c|c|c|c|c|c|c|}
\hline & $H C(n=20)$ & $\begin{array}{l}R A C D 40 L^{\text {hight }} \\
(n=18)\end{array}$ & $\begin{array}{l}R A C D 40 L^{\text {low }+} \\
(n=44)\end{array}$ & $\begin{array}{l}R A C D 4 O L^{\text {high }} \\
\text { versus } H C\end{array}$ & $\begin{array}{l}\text { RA CD } 40 L^{\text {low }+} \\
\text { versus HC }\end{array}$ & $\begin{array}{l}R A C D 40 L^{\text {high }} \\
\text { versus } R A \\
C D 40 L^{\text {low }+}\end{array}$ \\
\hline \multicolumn{7}{|c|}{ Activation antigens } \\
\hline CD69 (\%) & $4.0(2.0 ; 7.75)$ & $17.0(7.0 ; 25.25)$ & $14.0(8.25 ; 22.5)$ & $\mathrm{p}<0.001$ & $\mathrm{p}<0.001$ & NS \\
\hline CD25 (\%) & $13.0(9.5 ; 16.0)$ & $19.0(12.75 ; 22.25)$ & $19.0(13.0 ; 21.0)$ & $\mathrm{p}=0.042$ & $\mathrm{p}=0.009$ & NS \\
\hline HLA-DR (\%) & $0.0(0.0 ; 2.0)$ & $7.0(1.5 ; 17.0)$ & $2.0(0.0 ; 7.25)$ & $\mathrm{p}=0.009$ & $\mathrm{p}=0.032$ & NS \\
\hline CD39 (\%) & $5.0(3.0 ; 6.0)$ & $10.0(5.0 ; 27.0)$ & $5.0(3.0 ; 8.0)$ & $\mathrm{p}=0.019$ & NS & $\mathrm{p}=0.044$ \\
\hline \multicolumn{7}{|c|}{ Costimulatory molecules } \\
\hline CD27 (\%) & $93.5(88.0 ; 96.0)$ & $83.5(69.0 ; 97.0)$ & $83.0(75.0 ; 93.0)$ & NS & $\mathrm{p}=0.002$ & NS \\
\hline CD27- (\%) & $6.5(4.0 ; 12.0)$ & $16.5(3.0 ; 31.0)$ & $17.0(7.0 ; 28.0)$ & NS & $\mathrm{p}=0.002$ & NS \\
\hline CD28 (\%) & $98.0(96.0 ; 100.0)$ & $98.0(91.0 ; 100.0)$ & $96.0(93.0 ; 98.0)$ & NS & $\mathrm{p}=0.026$ & NS \\
\hline CD28- (\%) & $2.0(0.0 ; 4.0)$ & $2.0(0.0 ; 9.0)$ & $4.0(2.0 ; 7.0)$ & NS & $\mathrm{p}=0.026$ & NS \\
\hline
\end{tabular}

Percentage of PB CD4+ T cells expressing the activation antigens CD69, CD25, HLA-DR and the costimulatory molecules CD27 and CD28 are shown. The percentage of PB CD4+ T cells lacking the expression of CD28 (CD28-) and CD27 (CD27-) are listed, too. Medians and $25 \%$ and $75 \%$ percentile ranks (in parentheses) are given. Statistical significance between groups (healthy controls (HC), RA CD40L hight and RA CD40L Low+ patients) was determined by Mann-Whitney rank sum test. p Values $>0.05$ were considered to be not statistically significant (NS).

significant at a $\mathrm{p}$ value $<0.05$. Correlation was estimated by Spearman rank correlation. Correlation was considered at a $\mathrm{p}$ value $<0.05$.

\section{Results}

Expression of CD40L on PB CD4+ T cells was evaluated in 62 RA patients and $20 \mathrm{HC}$ by two colour flow cytometry. CD40L expression was significantly increased in RA patients (median $6.5 \%$ ) in comparison with HC (median $2.5 \%$, $\mathrm{p}<0.001)$. In addition, CD40L was strongly expressed on $>10 \%$ of CD4+ T cells in 18 of $62(29 \%)$ of RA patients but 0 of $20(0 \%)$ of HC (fig 1). These data were obtained by using the anti-CD40L-antibody TRAP1 and could be confirmed by using two other antibodies directed against CD40L (clone 89-76 and 24-31). According to the percentage and density of antigen expression of CD40L two groups of RA patients could be determined: patients with $\leqslant 10 \%$ CD $40 \mathrm{~L}+\mathrm{CD} 4+\mathrm{T}$ cells (RA CD40L lowt $)$ and patients with $\leq 10 \%$ CD40L+ CD4+ T cells (RA CD40L ${ }^{\text {high+ }}$ ) (fig 2). Table 1 shows the clinical characteristics of both patient groups. There were no differences between these groups with regard to disease duration, age of patients, male/female ratio, state of disease, occurrence of extra-articular features and medication. Remarkably, 0 of 18 $(0 \%)$ patients were in clinical remission in the RA CD40L ${ }^{\text {hight }}$ subgroup, whereas 9 of 44 $(21 \%) \mathrm{CD}_{40 \mathrm{~L}^{\text {low }}}$ patients fulfilled the ACR

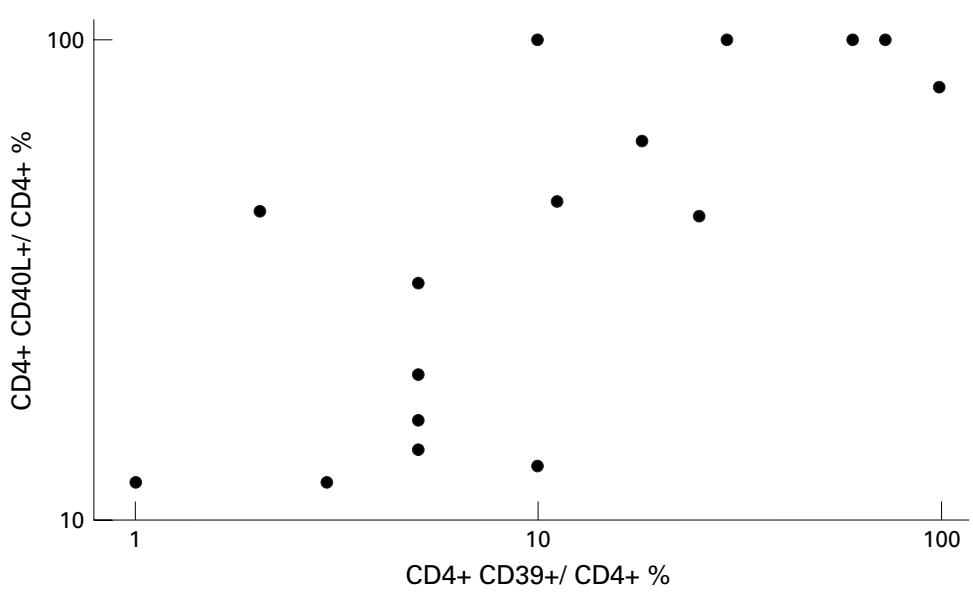

Figure 4 The percentage of CD39+CD4+T cells correlated significantly $(p<0.001)$ with the expression of CD40L in the RA CD4OL hight group as determined by Spearman rank correlation. Data are shown in logarithmic scale. preliminary criteria for complete clinical remission ${ }^{14}$ at the time of analysis $(p=0.049)$. The percentage of patients with an increased CRP level was higher in the $\mathrm{CD} 40 \mathrm{~L}^{\text {hight }}$ subgroup $(83 \%)$ than $C D 40 L^{\text {low }+}$ patients $(64 \%)$. In addition, a positive RF was more often observed in CD40L $\mathrm{L}^{\text {hight }}(89 \%)$ than CD40L ${ }^{\text {low }+}(73 \%)$ patients. Eight of 18 CD40L ${ }^{\text {hight }}$ patients and 8 of $44 \mathrm{CD}_{40 \mathrm{~L}^{\text {low }}}$ patients were reanalysed several months later. The percentage of CD40L+CD4+ T cells remained $>10 \%$ in seven of eight $\mathrm{CD} 40 \mathrm{~L}^{\text {hight }}$ patients showing, however, a tendency to decline under intensified immunosuppressive treatement - that is, increased doses of prednisone in all patients and initiation of a new/additional DMARD medication (sulfasalazine, hydroxychloroquine and cyclosporin A) in three patients (fig 3). These patients did not achieve clinical remission and inflammatory laboratory markers remained increased. Within the CD40L ${ }^{\text {lowt }}$ subgroup, expression of CD40L on CD4+ T cells did not exceed $10 \%$ on repeated analysis. Clinically, these patients had stable disease. SF was investigated in $10 \mathrm{RA}$ patients with CD40L being expressed on a significantly higher percentage of SF than PB CD4+ T cells in CD40L lowt patients $(p<0.001)$. Of the CD $40 \mathrm{~L}^{\text {hight }}$ patient group, two matched samples of $\mathrm{PB}$ and SF were obtained for analysis. Remarkably, in both patients CD40L was expressed on a higher percentage of PB than SF CD4+ T cells. In ST obtained from one of these two CD40L hight patients, immunofluorescence microscopy revealed CD40L expression on infiltrating mononuclear cells.

Coexpression of the activation antigens CD69, CD25, HLA-DR and CD39 as well as the costimulatory molecules CD27 and CD28 was studied on CD4+ T cells. Results are summarised in table 2. The expression of CD69, CD25 and HLA-DR was significantly increased in the CD40L ${ }^{\text {hight }}$ and CD40L ${ }^{\text {lowt }}$ subgroup when compared with HC. Between the two RA subgroups no differences in the expression of these activation antigens could be detected. In contrast, the expression of the activation antigen CD39 was significantly increased in the CD40L ${ }^{\text {hight }}$ group $(\mathrm{p}=0.044)$ in comparison with the CD40L lowt patients. Moreover, expression of CD40L and CD39 on 
CD4+ $\mathrm{T}$ cells correlated positively in CD40L hight patients as could be shown by Spearman rank correlation (correlation coefficient $0.765, \mathrm{p}<0.001$ ) (fig 4 ). No difference in the expression of CD39 could be observed between CD40L ${ }^{\text {lowt }}$ patients and HC. Expression of the costimulatory molecules CD27 and CD28 showed similar results in both RA subgroups. The percentage of $\mathrm{T}$ cells lacking the expression of CD27 and CD28 was increased in RA patients in comparison with HC. Statistically significant differences in antigen expression could, however, only be detected between $\mathrm{CD}_{40 \mathrm{~L}^{\text {low }}}$ patients and $\mathrm{HC}$ (CD27: $\mathrm{p}=0.002$; CD28: $\mathrm{p}=0.026)$.

\section{Discussion}

The signalling between the TNFR CD40 and its ligand CD $40 \mathrm{~L}$ plays a crucial part in the immune system contributing to cell mediated as well as humoral immune responses. ${ }^{3-5}$ It is known that CD40L forms a homotrimeric complex on the surface of activated $\mathrm{T}$ cells, to which three CD40 molecules can bind by fitting into the interface between adjacent CD40L monomers. ${ }^{15}{ }^{16}$ CD40 receptor binding to CD40L trimer induces clustering of the receptors thus initiating signal transduction. ${ }^{23}$

In RA, the chronic tissue destructive process has been attributed to an ongoing antigen driven immune response in which activated $\mathrm{T}$ cells play an important inflammatory part. ${ }^{12}$ Numerous CD40L-CD40 mediated inflammatory reactions such as induction of proinflammatory cytokines and NO production as well as upregulation of costimulatory activity of dendritic cells and monocytes/macrophages ${ }^{34}$ are known to be of functional and pathogenetic relevance in this destructive joint disease. In particular, CD40-CD40L interaction regulates IL12 production of dendritic cells, which is required for induction of Th1 type responses. ${ }^{4}$ As RA has been identified as a Th1 cell type mediated disease, this pathogenetic pathway may be another important function of CD40LCD40 interaction. ${ }^{17}$ Furthermore, CD40L+ T cells infiltrating the joints in RA could interact with CD40+ synovial fibroblasts causing their proliferation and upregulation of CD54 (ICAM-1), ${ }^{18}$ which could result in further recruitment of inflammatory cells in the synovium, as well as increasing the production of tumour necrosis factor $\alpha$, the key inflammatory cytokine in RA. ${ }^{19}$

In a recent study, MacDonald et $a l^{20}$ showed expression of CD40L mRNA by PB and SF T cells from RA patients, whereas CD40L cell surface expression was only observed on a small percentage of PB and SF T cells. In contrast with this study we provide evidence that CD40L is strongly expressed on CD4+ T cells in a particular subset of RA patients (29\%) thus phenotypically defining a CD40 $\mathrm{L}^{\text {hight }} \mathrm{RA}$ subgroup. CD40L expression was significantly higher in SF than $\mathrm{PB}$ of $\mathrm{CD} 40 \mathrm{~L}^{\text {lowt }} \mathrm{RA}$ patients; however, simultaneous analysis of $\mathrm{PB}$ and $\mathrm{SF}$ in 2 of $18 \mathrm{RA} \mathrm{CD} 40 \mathrm{~L}^{\text {hight }}$ patients revealed a higher percentage of CD40L+ CD4+ $\mathrm{T}$ cells in PB than SF. In one of these two CD40L ${ }^{\text {hight }}$ patients CD40L expression was, however, documented in ST. Hence, one might speculate that CD40L+CD4+ $\mathrm{T}$ cells preferentially migrate from $\mathrm{PB}$ into the synovial tissue, where they may interact with CD40 being expressed on different cell types in particular on synovial fibroblasts. ${ }^{19} 20$

In addition, expression of several activation antigens and costimulatory molecules was investigated on CD4+ T cells. In accordance with previous studies, ${ }^{21-24}$ the expression of very early, early and late activation antigens as CD69, CD25 and HLA-DR on PB CD4+ T cells of RA patients was significantly increased in the RA CD40L $\mathrm{L}^{\text {hight }}$ and RA CD40L low+ subgroups compared with HC. There were no differences in the expression of these antigens between RA CD40L ${ }^{\text {hight }}$ and RA CD40L low+ patients and expression of these antigens could not be correlated with CD40L expression. Interestingly, expression of CD39, a lymphoid activation marker with prolonged expression after activation, ${ }^{25}$ mediating homotypic adhesion $^{25} 26$ and showing ecto-apyrase activity, ${ }^{27}$ was significantly increased and positively correlated with CD40L expression in the RA CD40L ${ }^{\text {hight }}$ group. Thus, CD40L+CD39+ CD4+ $\mathrm{T}$ cells probably constitute a distinct subset of CD4+ $\mathrm{T}$ lymphocytes that have undergone prolonged and increased activation. On repeated analysis, expression of CD40L showed intraindividual variability. This observation strongly argues against a genetic control of CD40L expression in the RA CD40L ${ }^{\text {hight }}$ subgroup and favours the hypothesis of different lymphocyte activation levels at distinct phases of disease.

In agreement with recent results ${ }^{28-30} \mathrm{CD} 4+\mathrm{T}$ cells lacking expression of the costimulatory molecule CD28 were augmented in the investigated RA cohort. Remarkably, an increased percentage of CD28- CD4+ T cells was only found within the RA CD40L ${ }^{\text {low }+}$ subgroup. Similarly, the percentage of CD4+ T cells lacking the costimulatory molecule CD27, another member of the TNFR family being expressed on discrete subpopulations of $\mathrm{T}$ and $\mathrm{B}$ cells and providing costimulatory signals for $\mathrm{B}$ and $\mathrm{T}$ cell proliferation, ${ }^{31}$ was increased in the RA CD40L ${ }^{\text {low }+}$ subset. This is in accordance with a previous report by Kohem et $a .^{32}$

So far, it seems that strong expression of CD40L on CD4+ $\mathrm{T}$ cells reflects augmented and prolonged activation of lymphocytes. Remarkably, CD40L expression correlated with increased disease activity as the percentage of patients with increased CRP level and positive RF was higher in the RA CD40L ${ }^{\text {hight }}$ than in the RA CD40L ${ }^{\text {lowt }}$ subgroup. Furthermore, the percentage of RA CD $40 \mathrm{~L}^{\text {hight }}$ patients $(0 \%)$ in clinical remission of disease was significantly lower than that of $\mathrm{CD} 40 \mathrm{~L}^{\text {low }}$ patients $(21 \%)$. Thus, the expression of CD 40L is associated with active disease and possibly an unfavourable prognosis. This probably may be attributable to chronic and prolonged activation of $\mathrm{T}$ lymphocytes and consecutively raised and prolonged inflammatory activity of disease. Interestingly, expression of CD40L was not restricted to very early 
stages of disease, but also observed after 5-12 years disease duration.

The therapeutic significance of our observations remains to be investigated. In SLE, encouraging results have been obtained in mice with an anti-CD40L antibody treatment. This applies in particular to the onset of renal disease, which could be delayed by antiCD40L-antibody treatment. ${ }^{10}$ Preliminary experiments have also reported a beneficial effect of anti-CD40L antibody treatment in collagen induced arthritis of mice when applied at the time of immunisation. ${ }^{33}$ As pointed out above, numerous cell-cell interactions that are essential for the chronic disease process in RA could theoretically be disrupted by giving antiCD40L antibody. The finding that CD $40 \mathrm{~L}$ is hyperexpressed in a subset of RA patients may thus have implications for evaluating this antibody in human RA and anti-CD40L antibody treatment may finally prove to be a novel, rather specific immunotherapeutic approach in this particular subgroup of patients.

1 Noelle RJ, Roy M, Shepherd DM, Stamenkovic I, Ledbetter JA, Aruffo A. A 39-kDa protein signal for an activated helper T cells binds CD40 and transduces the signal for cognate activation of $\mathrm{B}$ cell. Proc Natl Acad Sci $1992 ; 89: 6550-4$

2 Gravestein LA, Borst J. Tumor necrosis factor receptor family members in the immune system. Semin Immunol 1998; 10:423-34.

3 Vogel LA, Noelle RJ. CD40 and its crucial role as a member of the TNFR family. Semin Immunol 1998;10:435-42.

4 Grewal IS, Flavell RA. CD40 and CD154 in cell-mediated immunity. Annu Rev Immunol 1998;16:111-35.

5 Clark LB, Foy TM, Noelle RJ. CD40 and its ligand. Adv Immunol 1996;63:43-78.

6 Callard RE, Armitage RJ, Fanslow WC, Spriggs MK. CD40 ligand and its role in $\mathrm{X}$-linked hyper-IgM syndrome. Immunol Today 1993;14:559-64.

7 Desai-Mehta A, Lu L, Ramsey-Goldman R, Datta SK. Hyperexpression of CD40 ligand by B and $T$ cells in Hyperexpression of CD40 ligand by $\mathrm{B}$ and $\mathrm{T}$ cells in human lupus and its role in pathogenic a

8 Koshy M, Berger D, Crow MK. Increased expression of CD40 ligand on systemic lupus erythematosus lymphocytes. J Clin Invest 1996;98:826-37.

9 Mohan C, Shi Y, Laman JD, Datta SK. Interaction between CD40 and its ligand gp39 in the development of murine lupus nephritis. J Immunol 1995;154:1470-80.

10 Early GS, Zhao W, Burns CM. Anti-CD40 ligand antibody treatment prevents the development of lupus-like nephritis
in a subset of New Zealand black x New Zealand white mice. Response correlates with the absence of an anti-antibody response. J Immunol 1996;157:3159-64.

11 Datta SK, Kalled SL. CD40-CD40 ligand interaction in autoimmune disease. Arthritis Rheum 1997;40:1735-45.

12 Fox DA. The role of T cells in the immunopathogenesis of rheumatoid arthritis: new perspectives. Arthritis Rheum 1997;40:598-609.

13 Arnett FC, Edworthy SM, Bloch DA, McShane DJ, Fries JF, Cooper NS, et al.The American Rheumatism Association 1987 revised criteria for the classification of toid arthritis. Arthritis Rheum 1988;31:315-24.
14 Pinals RS, Baum J, Bland J, Fosdick WM, Kaplan SB, Masi AT, et al Preliminary criteria for clinical remission in rheuAT, et al. Preliminary criteria for clinical remissio
matoid arthritis. Bull Rheum Dis 1982;32:7-10.

15 Hsu YM, Lucci J, Su L, Ehrenfels B, Garber E, Thomas D. Heteromultimeric complexes of CD40 ligand are present on the cell surface of human T lymphocytes. J Biol Chem 1997;272:911-15.

16 Karpusas M, Hsu YM, Wang JH, Thompson J, Lederman S, Chess L, Thomas D. A crystal structure of an extracellular fragment of human CD40 ligand. Structure 1995;3: 1031-9.

17 Müller B, Gimsa U, Mitchison NA, Radbruch A, Sieper J, Yin $\mathrm{Z}$. Modulating the Th1/Th2 balance in inflammatory arthritis. Springer Semin Immunpathol 1998;20:181-96.

18 Yellin MJ, Winikoff S, Fortune SM, Baum D, Crow MK, Lederman S, et al. Ligation of CD40 on fibroblasts induces CD54 (ICAM-1) and CD106 (VCAM-1) upregulation and IL-6 production and proliferation. J Leukoc Biol 1995; 58:209-16.

19 Harigai M, Hara M, Nakazawa S, Fukasawa C, Ohta S, Sugiura $\mathrm{T}$, et al. Ligation of CD40 induced tumor necrosis factor-alpha in rheumatoid arthritis: a novel mechanism of activation of synoviocytes. J Rheumatol 1999;26:1035-43.

20 MacDonald KP, Nishioka Y, Lipsky PE, Thomas R. Functional CD40 ligand is expressed by $\mathrm{T}$ cells in rheumatoid arthritis. J Clin Invest 1997;100:2404-14.

21 Afeltra A, Galeazzi M, Sebastiani GD, Ferri GM, Caccavo D, Addessi MA, et al. Coexpression of CD69 and HLADR activation markers on synovial fluid $\mathrm{T}$ lymphocytes of patients affected by rheumatoid arthritis: a three-colour patients affected by rheumatoid arthritis: a three-colc

22 Hovdenes J, Gaudernack G, Kvien TK, Egeland T. Expression of activation markers on CD4+ and CD8+ cells from synovial fluid, synovial tissue, and peripheral blood of patients with inflammatory arthritides. Scand J Immunol 1989;29:631-9.

23 Maurer D, Felzmann T, Holter W, Petera P, Smolen J, Knapp W. Evidence for the presence of activated CD4 T cells with naive phenotype in the peripheral blood of patients with rheumatoid arthritis. Clin Exp Immunol 1992;87:429-34.

24 Ichikawa Y, Shimizu H, Yoshida M, Arimori S. Activation antigens expressed on T-cells of the peripheral blood in Sjogren's syndrome and rheumatoid arthritis. Clin Exp Rheumatol 1990;8:243-9.

25 Kansas GS, Wood GS, Tedder TF. Expression, distribution, and biochemistry of human CD39. Role in activationassociated homotypic adhesion of lymphocytes. J Immunol 1991;146:2235-44.

26 Maliszewski CR, Delespesse GJ, Schoenborn MA, Armitage RJ, Fanslow WC, Nakajima T, et al. The CD39 lymphoid cell activation antigen. Molecular cloning and structural characterization. J Immunol 1994;153:3574-83.

27 Wang TF, Guidotti G. CD39 is an ecto-(Ca2+, Mg2+)apyrase. J Biol Chem 1996;271:9898-901.

28 Schmidt D, Goronzy JJ, Weyand CM. CD4+ CD7- CD28$\mathrm{T}$ cells are expanded in rheumatoid arthritis and characterized by autoreactivity. J Clin Invest 1996;97:2027-37.

29 Martens PB, Goronzy JJ, Schaid D, Weyand CM. Expansion of unusual CD4+ T cells in severe rheumatoid arthritis. Arthritis Rheum 1997;40:1106-14

30 Namekawa T, Wagner UG, Goronzy JJ, Weyand CM. Functional subsets of CD4 $\mathrm{T}$ cells in rheumatoid synovitis. Arthritis Rheum 1998;41:2108-16.

31 Lens SMA, Tesselaar K, van Oers MHJ, van Lier RAW. Control of lymphocyte function through CD27-CD70 interactions. Semin Immunol 1998;10:491-9.

32 Kohem CL, Brezinschek RI, Wisbey H, Tortorella C, Lipsky PE, Oppenheimer-Marks N. Enrichment of differentiated CD45RB ${ }^{\text {dim }}, C D 27-$ memory $T$ cells in the peripheral blood, synovial fluid, and synovial tissue of patients with rheumatoid arthritis. Arthritis Rheum 1996;39:844-54

33 Durie FH, Fava RA, Foy TM, Aruffo A, Ledbetter JA, Noelle RJ. Prevention of collagen-induced arthritis with an antibody to gp39, the ligand of CD40. Science 1993;261: $1328-30$. 